\title{
Status, Distribution, and Management of Mountain Goats in the Greater Yellowstone ECOSYSTEM
}

\author{
JOHN W. LAUNDRÉ \\ Department of Biological Sciences — IdAho State University \\ PocATELLO
}

Mountain goats (Oreamnos americanus) are not thought to be historic natives to the Greater Yellowstone Ecosystem. They occurred in the area before 10,000 B.P. but all evidence indicates they were extirpated from the area by the time Europeans arrived. The Idaho Department of Fish and Game and the Montana Department of Fish, Wildlife, and Parks introduced goats into the area in the mid 1900's. Goats have expanded in numbers and range and are occasionally seen within Yellowstone and Grand Teton National Parks. There is concern that their presence in the Parks might negatively impact native plants and animals. This study assessed the current distribution of mountain goats and their potential impact on fauna and flora of the Parks. The current distribution of mountain goats in the Greater Yellowstone Ecosystem was determined by consulting area resource managers, perusing sighting records, and conducting field surveys. The potential impact of goats on the fauna and flora of Yellowstone and Grand Teton Parks was assessed by compiling all available information on mountain goat behavior and ecology.

Mountain goat distribution within the Greater Yellowstone Ecosystem has not changed significantly from previously reported accounts. If goats colonize either Park, low and high population levels of 95 and 500 for Yellowstone and 160 and 500 for Grand Teton Parks were estimated. Based on existing literature, little impact of goats on vegetation and the physical environment is anticipated in either Park. The main wildlife species that goats may impact would be bighorn sheep (Ovis canadensis). Food habits and habitat requirements of mountain goats and bighorn sheep overlap. However, in sympatry, investigators have found minimal overlap in specific foods used and habitat selected. At low populations of goats, no negative impact on sheep in Yellowstone is anticipated. In Grand Teton National Park, even low numbers of goats may impact sheep because of constricted sheep winter range. Goats are expected to negatively impact sheep in both Parks at high density estimates. At this time, it is difficult to predict future population trends of goats and their total impact on the two Parks.

If the National Park Service classifies goats as exotic to the Greater Yellowstone Ecosystem, Park personnel will have to develop a management plan for them. Three management alternatives are presented: No action, limited control of mountain goats, and total elimination of goats within Park boundaries. Of the three alternatives, it is recommended no action be taken. However, a multi-option plan should be formulated to respond to whatever changes in goat numbers and distribution occur in the future. 